\title{
Accident Analysis and Identification of Black Spots on the Motorways in Pakistan - a Reliability Analysis Approach
}

\author{
Muhammad Hussain ${ }^{1 \mathrm{a}}$, Jing SHI ${ }^{1 \mathrm{~b}}$, Yousaf Ali ${ }^{1 \mathrm{c}}$ \\ RECEIVED ON 11.04.2020, ACCEPTED ON 20.12.2020
}

\begin{abstract}
The objective of this study is to explore the contributory factors responsible for road accidents and identifies the black spots on the three motorways; M1 (Peshawar-Islamabad), M2 (Islamabad-Lahore), and M3 (Pindi BhattianFaisalabad) in Pakistan. Five years' road accident data was obtained from the National Highways and Motorway Police (NHMP), Pakistan. The database of this study included six hundred road accidents on atotal of 574 kilometers long routes of M1, M2 and M3. The reliability analysis approach was used to locate black spot locations on each motorway. For the visualization and mapping of black spots on each motorway, a Geographic Information System (GIS) was used. The results explored that vehicle condition was the significant contributory factor responsible for the maximum number of road accidents on M1 and M3, while for M2, it was drowsy driving. It is also found that a maximum number of road accidents on M2 and M3 occurred in late-night, while for M1, it was day timing. Furthermore, road accidents were relatively higher in May-July and December on M1 and M2, which shows that extreme weather influences the occurrence of road accidents. On the contrary, no substantial variation of road accidents was examined for M3 month-wise. Finally, black spots on each motorway were located and their georeferenced coordinates were presented for future use. As a result, precautionary measures and provisions are suggested for concerned authorities to mitigate road safety problems.
\end{abstract}

Keywords: Road Accidents, Motorways, Contributory Factor, Geographic Information System, Black Spots.

\section{INTRODUCTION}

$\mathrm{N}$ owadays, the utmost detrimental consequences of developing a modern transportation system are road accidents, as these are responsible for a substantial number of fatalities and injuries. According to a global status report on road safety 2018 , the fatality rate due to road accidents is unacceptably high (1.35 million per year) [1]. Road accidents have become the $8^{\text {th }}$ leading cause of fatalities among all age groups. The number of injuries is even higher than the number of fatalities. As compared to high-income countries, the number of road accidents is higher in low and middle-income countries [2]. In middle-income countries like Pakistan, road accidents are the leading cause of fatalities. The road transport culture is void of the safety-oriented system in Pakistan. There are no strict criteria for the issuance of driving license and proper driving training, which turn these vehicles into killing machines on our roads. For instance, it is found that driving without a driving license and proper driving training is a significant predictor of road accidents among Pakistani drivers [3]. Road accidents negatively affect the driver's health and produce substantial financial consequences on his/her family. According to World Bank data, road accidents cost nearly 1-3 percent of the total Gross Domestic Product (GDP) of a country [4].

The main factors involved in road accidents are road,

${ }^{1}$ Institute of Transportation Engineering, Tsinghua University, Beijing 100084, China.

Email: hussainm10@mails.tsinghua.edu.cn, bjingshi@tsinghua.edu.cn (Corresponding Author), cysf18@mails.tsinghua.edu.cn

This is an open access article published by Mehran University of Engineering and Technology, Jamshoro under CC BY 4.0 International License. 
vehicle, and human factors (drivers). Skill level [6], lack of experience [7], driving recklessly [8], excessive speed [8, 9], risky driving behaviors [10], traffic violations [9], driver errors at intersections [11], age-related decline in visual, cognitive and mobility functioning [12], failure to comply with signs and signals, failure to see other vehicles and road users, failure to yield right of way, and improper turns and lane changes [6] have been implicated in the road accidents among drivers. Low visibility, poor road surface conditions, high winds and low temperatures are also associated with an increasing number of road accidents [13, 14]. Around 14\% of accidents are caused by roads that are poorly laid out, in poor condition, or have slippery surfaces [15]. Weather conditions are also found to be associated with an increasing number of road accidents. In 2017, road accidents in India were analyzed, and it was reported that the rate of accidents is relatively higher in high temperature (May-June) and low temperature (December-January) as compared to other months [16], which shows that the extreme weather also influences the rate of road accidents. Furthermore, the time of the occurrence of an accident is an important factor pertaining to the accident rate. A study conducted in New Zealand reported that a substantial number of road accidents occur during morning rush hour, i.e., 07:45 and 08:30 hours, followed by 15:00 and 17:30 hours, respectively, which coincides with the school and office close time [13]. Excessive speed, untrained driving (wrong lane-changes, other violations, and careless driving), vehicle conditions and climatic conditions are found to be the leading causes of road accidents in China [2]. A comprehensive literature review of previous studies revealed several sub-factors: aggressive driving, untrained driving, drowsy driving, distracted driving, climatic conditions, light factors, geographical conditions and road design are accountable for road accidents [2, 17-19]. Traffic safety researchers and stakeholders should consider all the critical factors, and measures should be taken to prevent road accidents and increase road safety.

In the case of Pakistan, about a $2 \%$ yearly population increase and a $3.3 \%$ increase in rapid urbanization resulted in an $18.3 \%$ increase in motor vehicles for the last two decades [20]. The length of roads within Pakistan has not increased significantly in recent years, but the number of road accidents increased significantly. Pakistan's estimated accident death rate is 14.2 per 100,000 populations [1], which is worrying. According to the Pakistan Bureau of Statistics, approximately 48,828 people died in 93,350 recorded road accidents across the country [5]. The proportion of fatalities in road accidents is recorded by up to 55 percent until 2016, which is considered the highest in history [21]. Table 1 presents the number of road accidents of the last ten years (2008-2018) in Pakistan and the number of fatalities and injuries.

Motorways and highways are the primary sources of high-speed transport in the country. During the accident analysis of motorways and highways, different researchers have focused on relationship analysis of accidents and different contributory factors. Generally, the roads of Pakistan are divided into two major types; motorway and national highway.

\begin{tabular}{|c|c|c|c|c|c|}
\hline \multicolumn{7}{|c|}{ Table 1: Year-wise data of road accidents in Pakistan [5] } \\
\hline Years & Total accidents & Fatal accidents & Non-fatal accidents & No of fatalities & No. of injuries \\
\hline $2008-09$ & 9496 & 4145 & 5351 & 4907 & 11037 \\
\hline $2009-10$ & 9747 & 4378 & 5369 & 5280 & 11173 \\
\hline $2010-11$ & 9723 & 4280 & 5443 & 5271 & 11383 \\
\hline $2011-12$ & 9140 & 3966 & 5174 & 4758 & 10145 \\
\hline $2012-13$ & 8988 & 3884 & 5104 & 4719 & 9710 \\
\hline $2013-14$ & 8359 & 3500 & 4859 & 4348 & 9777 \\
\hline $2014-15$ & 7865 & 3214 & 4651 & 3954 & 9661 \\
\hline $2015-16$ & 9100 & 3591 & 5509 & 4448 & 11544 \\
\hline $2016-17$ & 9582 & 4036 & 5546 & 5047 & 12696 \\
\hline $2017-18$ & 11121 & 4829 & 6292 & 5948 & 14489 \\
\hline
\end{tabular}

Mehran University Research Journal of Engineering and Technology, Vol. 40, No. 4, October 2021 [p-ISSN: 0254-7821, e-ISSN: 2413-7219] 
As compared to the motorway, the national highway has more traffic signals and intersections. The motorways are designed on the outskirts of the city and connect major cities of Pakistan. It is a controlled access road, which provides a smooth movement of high-speed traffic without traffic signals. Access on the motorway is provided through ramps and slip roads. There are three initially built motorways in Pakistan; M1 (length=154 km) connects Peshawar and Islamabad, while M2 (length $=367 \mathrm{~km}$ ) is the longest motorway between Islamabad and Lahore. Pindi Bhattian and Faisalabad are connected by M3, having a length of $53 \mathrm{~km}$ only [5]. Fig. 1 shows the overall plan of the motorway system in Pakistan.

Traffic safety researchers often focused on the state of the art practices for data collection procedures, summarizing the data, identifying black spots and methods adopted to analyze road accidents [22-24]. Furthermore, the low-cost treatments to solve the road safety problems and remedial measures have also been well explored by safety researchers [25-27]. The identification of black spots of the road network is aimed at a comprehensive safety program by traffic safety officials, which is vigorous to improve road safety conditions of the areas. A theoretical definition of black spots from the previous researches can be induced that a black spot is any point that has a higher number of occurring accidents in comparison to similar road locations (i.e., within the same region or on the same road) [28]. Geographical Information System (GIS) technology has been used as a convenient tool to manage, explore, and visualize road accident data on the road network. There are several studies in which GIS tools are used to show the location of accidents on a digital map and analyze the black spots on the highway [29].

The contribution of this study spans over two dimensions. Firstly, it explores the contributory factors responsible for the maximum number of road accidents on M1, M2, and M3. Furthermore, the variation of road accidents based on the time of the day and month of the year is also explored. It is necessary to reduce road accidents by identifying the contributory factors responsible and present countermeasures that address the specific road safety concerns [30]. Secondly, to explore how and where road accident countermeasure can be implemented, the black spots are determined on each motorway by reliability analysis. Visualization and mapping of each black spot were conducted by applying the GIS technique.

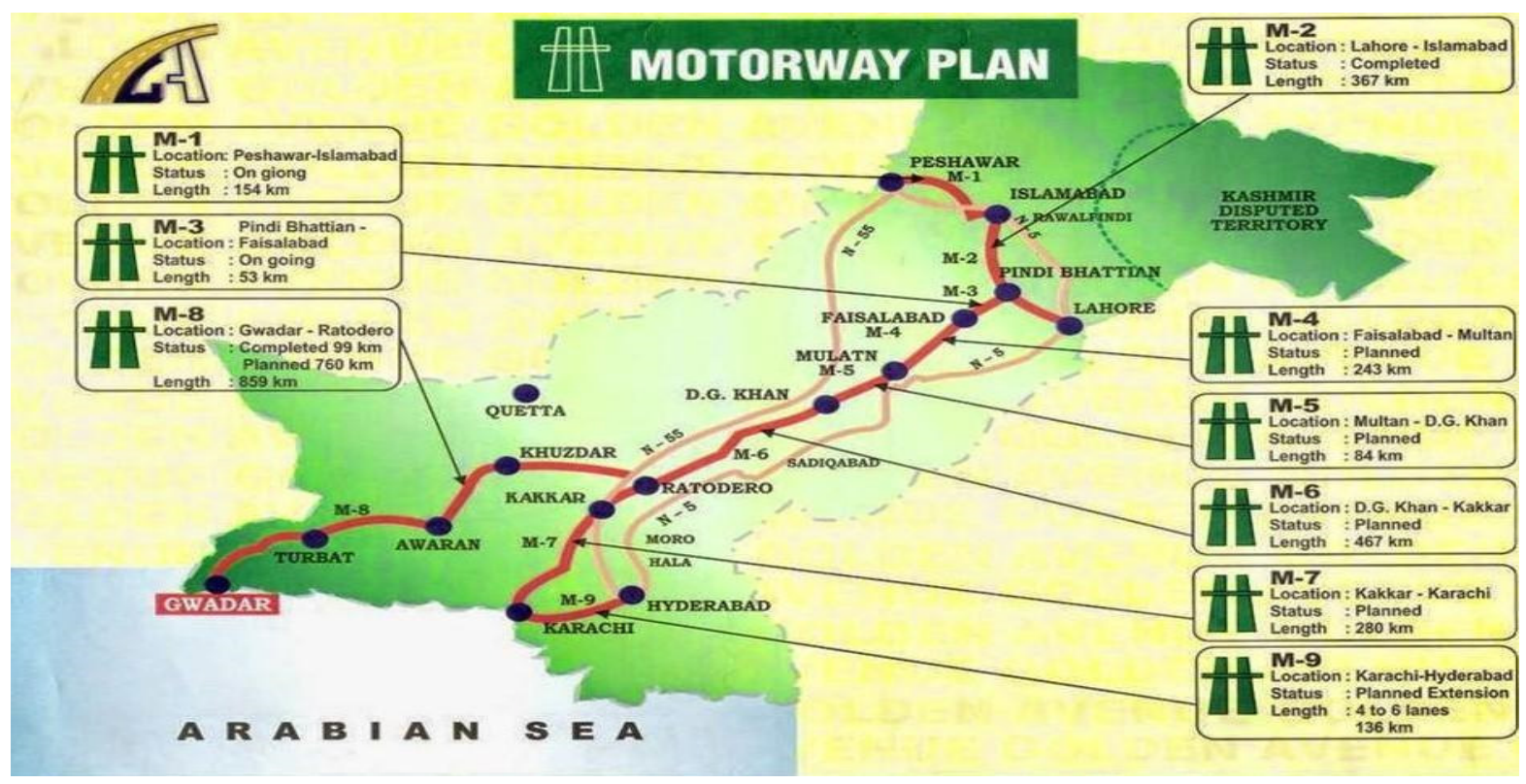

Fig. 1: Motorways system in Pakistan [Source: National Highway Authority, Pakistan] 


\section{DATA DESCRIPTION AND METHODOLOGY}

The study data comprises the road accidents on M1, M2, and M3 from 2013 to 2017, collected from the National Highways and Motorway Police (NHMP), Pakistan. More recent data was not available in a consistent format at the time of this study. Sorting of data was done using SPSS 25.0, based on contributory factors, time of the day and month of the year. Time was distributed to four slots; morning time (6:00 12:00), day time (12:00-18:00), night time (18:0000:00) and late-night (00:00-06:00). Based on the road accident data extracted from NHMP, the contributory factors responsible for road accidents were categorized into seven categories. After a comprehensive literature review, contributory factors mentioned in Table 2 are derived from the previous shreds of evidence. Moreover, after the careful analysis of road accident data (2013-2017) collected from the NHMP, Pakistan, it is further revealed that the identical contributory factors previously found in the literature are involved in road accidents on M1, $\mathrm{M} 2$, and M3. Based on the above-mentioned findings in the literature, the contributory factors are selected for the study. As it was difficult to examine each cause responsible for road accidents, the major contributory factors were categorized as mentioned in Table 2. It is also vigorous to collect accurate, precise and reliable traffic accident data for the proper precautionary measures. In Pakistan, road accident reports are usually prepared in textual forms, which makes it difficult to analyze, comprehensively. Traffic accident reports in Pakistan include accident parameters such as time and location of the accident, severity level, vehicle type, number of persons injured/killed and contributory factors responsible for accidents. It is vigorous to collect accurate, precise and reliable traffic accident data for the proper precautionary measures. Black spots on each motorway were explored based on the reliability analysis. The same technique was applied in Afyonkarahisar, Turkey, for the identification of black spots [31]. Using GIS, black spots were shown on the map by analyzing the spatial characteristics of identified locations. Black spots are geo-referenced for future use so that anyone can get the exact location of black spots on motorways.

\begin{tabular}{|l|l|}
\hline \multicolumn{2}{|c|}{ Table 2: Contributory factors involved in this } \\
study
\end{tabular}

\section{RESULTS AND DISCUSSION}

\subsection{Preliminary data analysis}

In this section, the difference of road accidents on the three motorways based on the day, month, and severity level is explored. The following sections present the road accident analysis on M1, M2, and M3 in Pakistan.

\subsubsection{Variation in the number of accidents on M1, $\mathrm{M} 2$ and M3 by contributory factors}

Fig. 2 portrays a clear image of different contributory factors responsible for road accidents on M1, M2, and M3. Overall, vehicle conditions, untrained driving, and drowsy driving contribute to the lion's share of road accident involvement.

From 2013 to 2017, vehicle condition was a significant factor in accidents on M1, having a considerable proportion $(35 \%)$ of accidents. The results of poor road conditions are engine failure and tire bursts, which ultimately lead to road accidents. Driving risks are often amplified by poor car maintenance, such as tires that do not provide a deep enough grip or are not 
properly inflated, causing road safety risks for drivers and other road users. Untrained and drowsy driving was ranked as second and third, having proportions of $27 \%$ and $17 \%$, respectively. The reason could be

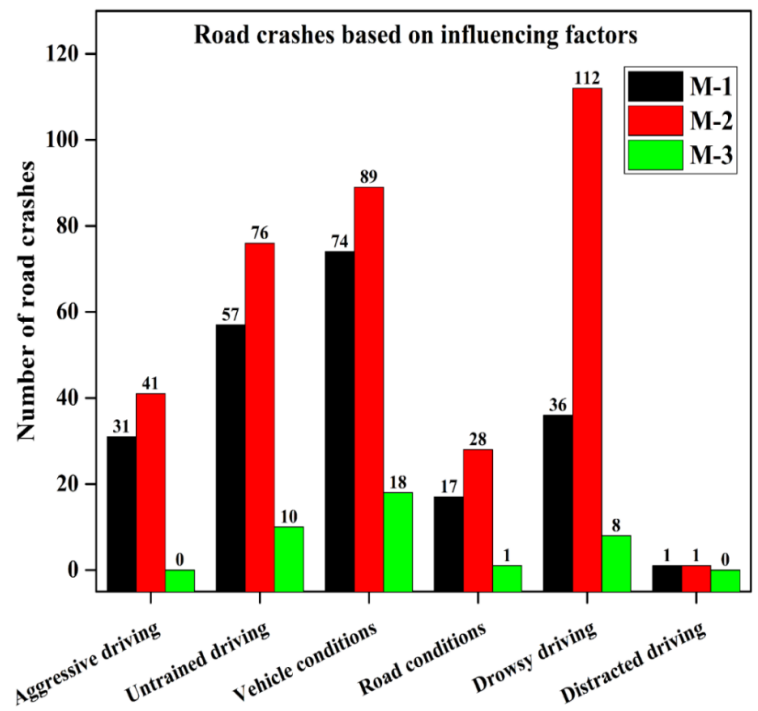

Fig. 2: Comparison of road accidents on motorways based on contributory factors

linked with the high mobility of motorways, which enables the driver to drive fast, resulting in more risk to the driver as well as other road users. Untrained drivers are usually unable to control the vehicle while driving at a very high speed and ultimately lead to the risk of road safety. A small proportion of road accidents were found based on other contributory factors such as; road condition, aggressive and distracted driving.

On M2, drowsy driving with its $33 \%$ contribution in accidents was a concrete reason and played a decisive role in the emergence of indelible road accidents. Sleep deprivation make lapses of attention more likely to occur and may play a role in behavior that can lead to accidents. It is worth noting that summer in Pakistan is scorching hot, with temperatures ranging above $40^{\circ} \mathrm{C}$. The excessive use of air conditioning in the vehicle in summer and the use of a heater in winter might account for the drowsiness of drivers. Furthermore, longer than 4-hour continuous driving causes fatigue and could be dangerous for road users. Vehicle conditions and untrained driving clinched second and third positions in this list, with $26 \%$ and
$22 \%$ of total accidents, respectively.

On M3, there is no substantial variation in the number of road accidents observed among contributory factors responsible for accidents; however, vehicle condition is ranked first. The reason for this factor is that most of the portion of M3 consists of the long and straight road, which stimulates the driver to drive recklessly. Empirical evidence shows that an average increase in the speed of $1 \mathrm{~km} / \mathrm{h}$ leads to a $3 \%$ increase in road accidents [36]. For car occupants having a car speed of $80 \mathrm{~km} / \mathrm{h}$, the likelihood of death in the accident is 20 times greater than a speed of $32 \mathrm{~km} / \mathrm{h}$ [35]. As compared with M1 and M3, the number of accidents on $\mathrm{M} 2$ is higher. One of the main reasons for the higher number of accidents on M2 is the length of the road. The entire stretch of M2 is $367 \mathrm{~km}$, while the lengths of M1 and M3 are $154 \mathrm{~km}$ and $53 \mathrm{~km}$, respectively. One hundred and two fatal accidents were reported on M2, while the fatal accidents on M1 and M3 are relatively less in number.

\subsubsection{Time-wise trend of road accidents on Motorways}

Fig. 3 represents the time-wise trend of road accidents on M1, M2, and M3.

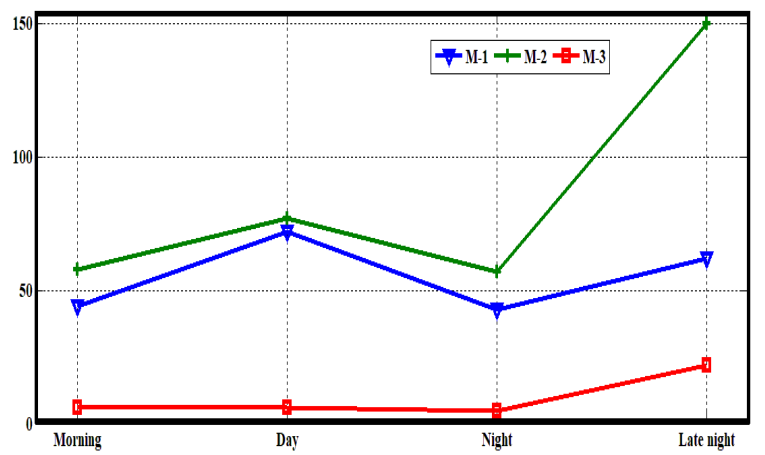

Fig. 3: Variation of number of road accidents by time of the day (M1, M2, and M3)

(Morning=06:00-12:00, Day=12:00-18:00,

Night $=18: 00-00: 00$, Late-night $=00: 00-06: 00$ )

No substantial difference in the number of accidents during different times of the day is evident in M1. Furthermore, road accidents on M1 are found to be relatively high in the daytime (06:00-12:00) compared to other times of the day, but this difference is not significant.

Mehran University Research Journal of Engineering and Technology, Vol. 40, No. 4, October 2021 [p-ISSN: 0254-7821, e-ISSN: 2413-7219] 
M2 suffered a significant portion of road accidents $(61 \%)$ during the night and late at night. Specifically, road accidents on M2 are relatively higher in the latenight time (00:00-06:00). There might be two reasons; the first is that many drivers rush to their destinations by driving fast in the late-night due to significant traffic volume reduction. This speed behavior ultimately causes some dangers for themselves as well as others. Secondly, the drivers feel sleepy late-night due to the absence of the hustle and bustle around. This drowsiness might be the reason for these accidents.

Road accidents remain constant and low on M3 in the morning, day, and night time.

\subsubsection{Month-wise trend of road accidents on Motorways}

To envisage the trend of road accidents in different months, the data of the last five years were analyzed. Fig. 4 shows the month-wise distribution of road accidents on M1, M2, and M3 from 2013 to 2017 in Pakistan.

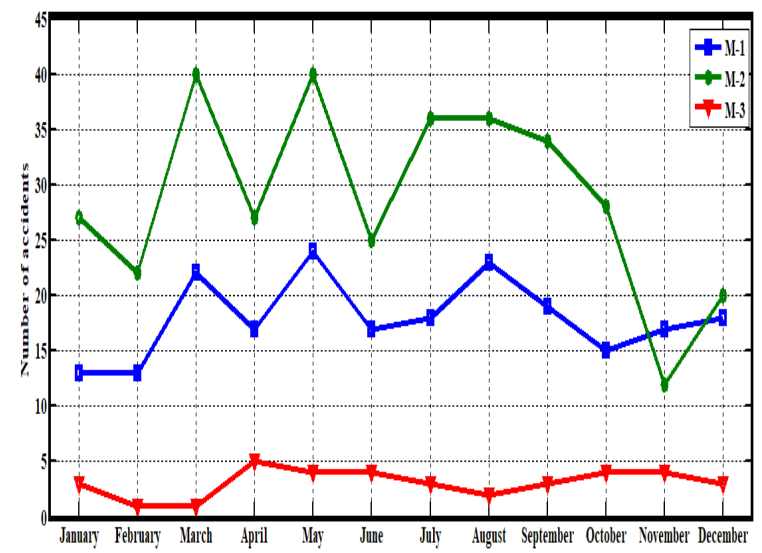

Fig. 4: Difference of road accidents by months (M1, $\mathrm{M} 2$ and M3)

For M1, monthly variation in road accidents is not substantial, but accidents are found to be relatively higher in May-July (summer) as compared to other months. The temperature from May to July is relatively high in Pakistan compared to other months; it might have had its impact on accidents because the high temperature on the road can cause tire burst, engine and brake failure while over speeding. This finding is in line with a previous study conducted in
India (a neighbor country of Pakistan), in which accidents were found to be relatively higher in extreme weather [16]. It is already shown in Section 3.1 that vehicle conditions and untrained driving are contributory factors responsible for the majority of accidents on M1.

For M2, road accidents are relatively higher in MayJuly and December, which reveals that extreme weather (highest in May-July and lowest in December) is responsible for increasing the number of accidents. There are certain psychological and physiological effects of high temperatures on drivers. Emotions arise with the temperature, people are more irritable to others, get tired, undergo sleepy conditions, and finally, their reaction time gets slower [16]. The occurrence of accidents at low temperatures (December) is also relatively high. The reason associated with this fact is that the driver uses the heater when driving, and the warmer environment inside the car compared to the outside renders the driver drowsy. This drowsiness has a detrimental effect on road safety.

For M3, no substantial variation was evident in the number of accidents among different months of the year.

\subsection{Identification of black spots on motorways using reliability analysis}

As mentioned earlier that black spot has the maximum number of road accidents compared to other locations on the same road. There are several techniques in which black spots are identified [32]. However, in this study, reliability analysis explores the black spots on the M1, M2, and M3. First of all, Poisson distribution is applied to estimate the number of accidents that occur at a specific location within a certain period [33]. Threshold values using the Poisson distribution for accident counts with 0.05 and 0.01 probability rates are used to identify the black spots. If the occurrence of accidents for a certain time is $Y$, which is a random variable and the observed number of accidents is y so, $\Lambda$ is the mean of $Y$, and where $\Lambda=\lambda, Y$ is the Poisson distribution with parameter $\lambda$. As the length of each motorway is long, it was not possible to analyze road accidents as a single unit. Therefore, the number of 
accidents is calculated in each $10 \mathrm{~km}$ segment of the motorways. The total number of segments on M1, M2, and M3 were found to be 15,36 , and 5, respectively. Segments are named in the form of chainage. Segmentation may lead to concise homogeneous segments of road sections, especially when there are multiple variables involved [34]. There were some statistical inference problems when the short segments are used for analyzing road accidents. Two frequency tables were created for the exploration of black spots on each motorway. The first frequency table contains the number of accidents on each $10 \mathrm{~km}$ long section of the whole motorway length. The second frequency table was calculated for the expected distribution based on Poisson distribution. The probability that a given number of accidents will occur in a $10 \mathrm{~km}$ long section is calculated first by finding the average number of accidents per section and presented in equation (1);

$\lambda=\frac{\mathrm{n}}{\mathrm{k}}$

where $\mathrm{n}$ is the number of accidents, $\mathrm{k}$ is the number of sections and $\lambda$ represents the average number of accidents per section. Equation (2) shows the probability function of the particular number of accidents occurring in each section;

$\mathrm{P}=\frac{\mathrm{e}^{-\lambda} \lambda^{\mathrm{x}}}{\mathrm{x} !}$ where $\mathrm{P}$ is the probability of $\mathrm{x}$ number of accidents per section, and e is the Euler's constant. To explore the difference between both frequency tables, the Chisquare test is used. The formula is shown in equation (3);

$\mathrm{X}^{2}=\sum_{1}^{\mathrm{k}} \frac{\left(\mathrm{f}_{0}-\mathrm{f}_{\mathrm{e}}\right)^{2}}{\mathrm{f}_{\mathrm{e}}}$

where $f_{o}$ and $f_{e}$ are the expected and observed number of accidents. Both the above-mentioned frequency tables are compared. If the observed distribution table has more sections than those of the table for the random distribution, then the features create a clustered pattern. The accident's clustered pattern is shown in Fig. 5. Besides, GIS is used to show the route map of M1, M2, and M3, as well as the location of black spots on M1, M2, and M3. The location is saved in the form of geo-referenced coordinates. The route map is analyzed to choose the black spots to check the elevation profile and terrain of M1, M2, and M3.

On M1, a total number of fifteen sections are identified in this study, and among them, only six were having a high accident rate as compared to the remaining parts. The digitalized imaginary route is shown in Fig. 6 (a). It is clear from the route imagery that the black spots are located at the start of M1, and it passes through the

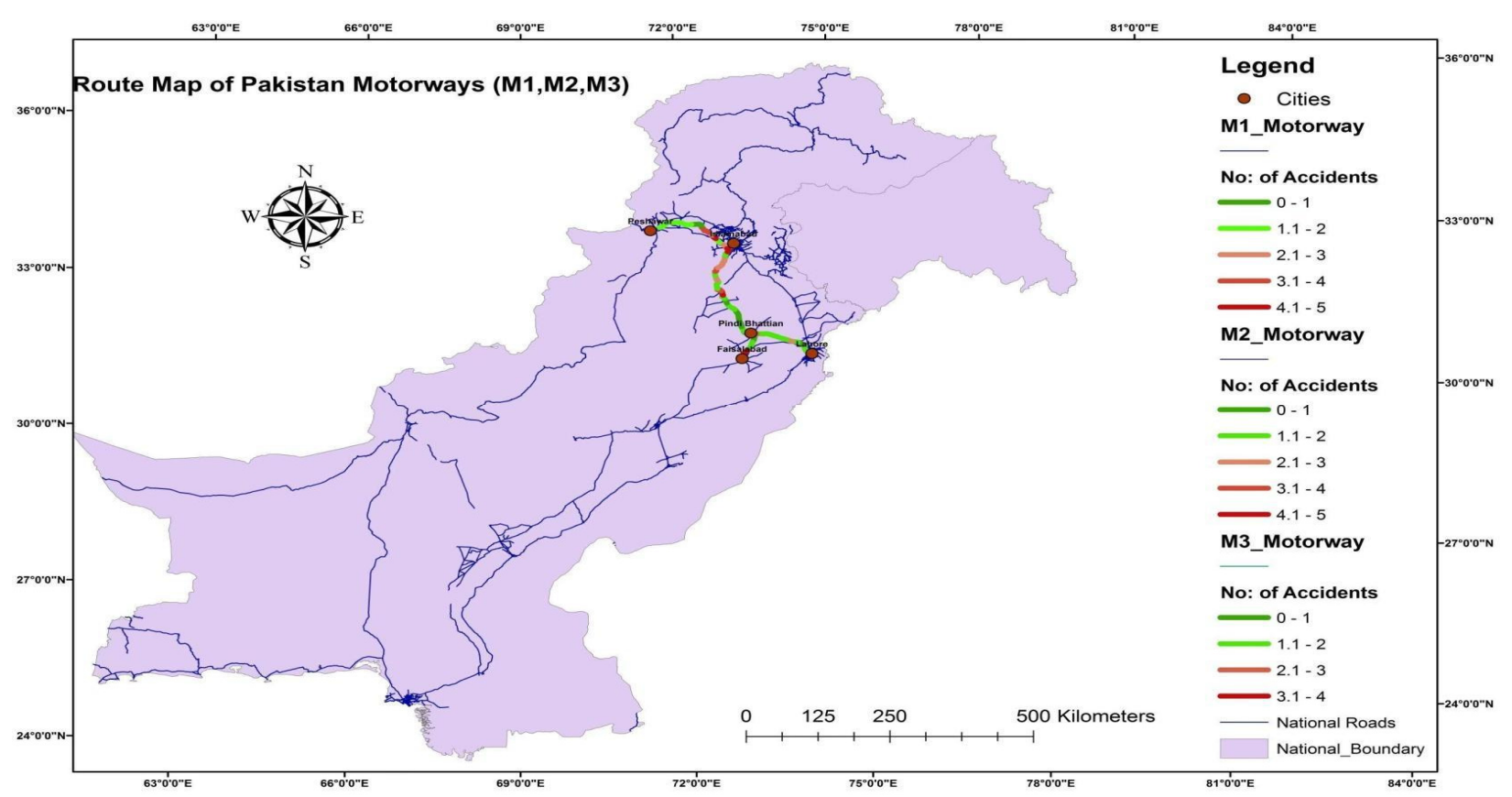

Fig. 5: Route mapping for identification of black spots 


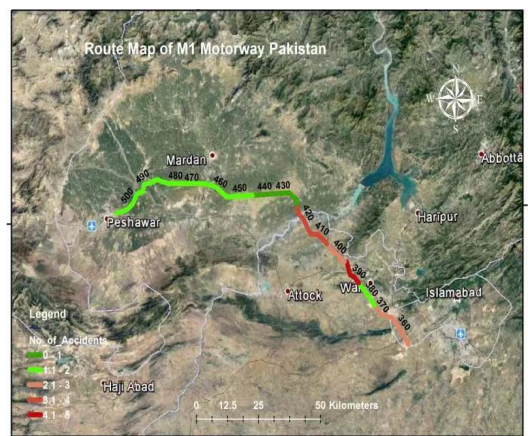

(a)

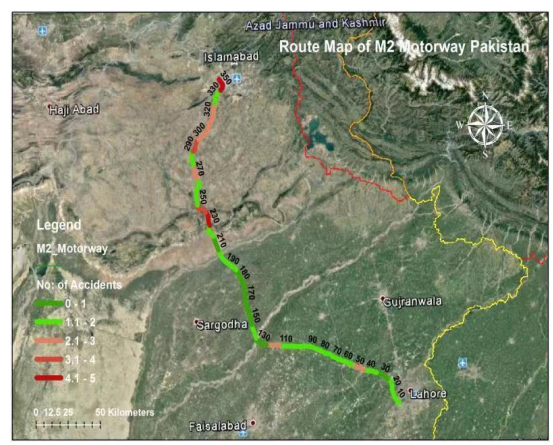

(b)

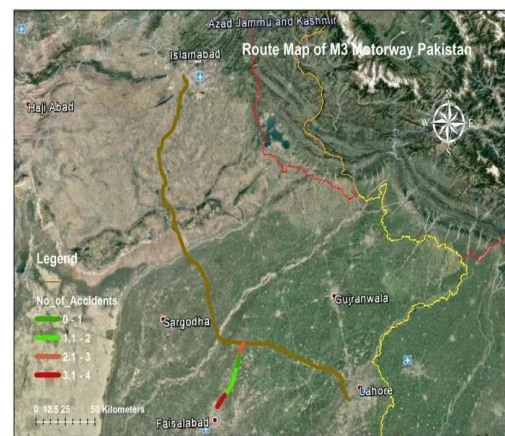

(c)

Fig. 6: Route mapping of M1 (a), M2 (b) and M3 (c) in Pakistan

interchanges of different cities like Burhan interchange and Swabi interchange. The reason for the black spots near the interchanges might be the high density of traffic in these cities. The black spot on M1 is located between Burhan and Swabi Interchange, and geo-referenced coordinates are [latitude $33.786336^{\circ}$, longitude $72.665600^{\circ}$ ] to [latitude $34.043681^{\circ}$, longitude $72.408362^{\circ}$ ].

The black spots on M2 are located in a tail region near Islamabad, which contains a highly mountainous area, Kallar Kahar. Kallar Kahar region carries curves and substantial slopes. The steep slopes can lead to brake failure, and lack of control on vehicles resulted in more accidents in this section. The most critical Kallar Kahar section has geo-referenced coordinates [latitude $32.642182^{\circ}$, longitude $72.762190^{\circ}$ ] to [latitude $32.776252^{\circ}$, longitude $72.717257^{\circ}$ ].

Two black spots on M3 (Pindi Bhattian to Faisalabad) are identified, and the digitalized imagery of that route is shown in Fig. 6 (c). It is clear from the figure that the black spots are located at the start and the end of M3, and it passes through the interchange of Faisalabad and Pindi Bhattian. The black spots are at the end sections of M3 since the tail end of this motorway has a high density of traffic; therefore, this section's accident rate is more compared to other sections. Another reason might be that this road contains a straight section, which motivates the drivers to speed faster. A straight road leads the drivers to over speeding, causing more accidents because of rapid braking and fast turning. The interchange of Faisalabad and Pindi Bhattian is the black spot on M3 and, the geo-referenced coordinates are [latitude $31.601560^{\circ}$, longitude $73.152394^{\circ}$ ] to [latitude $31.521538^{\circ}$, longitude $73.070181^{\circ}$ ].

\section{CONCLUSIONS}

Road safety has become the focus of discussion in the last two decades as it involves a substantial number of fatalities and injuries. Road accidents are preventable to a great extent. The risk of incurring injury in a road accident is mainly predictable, and many countermeasures, proven to be effective, exist. An integrated approach towards road safety, which involves the collaboration of different concerned authorities, can lead to a substantial road accident decrease. The integrated approach includes proper road design and traffic management, improved vehicle standards, and proper law enforcement [35]. In developing countries like Pakistan, current efforts to resolve road safety problems are not sufficient compared to developed countries. Despite the growing pattern of road accidents on the road, road safety has received scarce attention from concerned authorities in Pakistan. This study, therefore, focuses on the accident analysis and identification of black spots on the three motorways M1, M2 and M3 in Pakistan. This study undertakes a descriptive analysis to explore the contributory factors responsible for road accidents.

The analysis shows that the distribution of road accidents vary according to time and month. In general, there were several factors responsible for road accidents on the three motorways in the country, but overall vehicle conditions, drowsy driving and untrained driving are the most important factors accounted for $31 \%, 26 \%$ and $24 \%$, respectively. The 
other factors, like aggressive and distracted driving and road conditions, also play a minor role in road accidents. On M1, vehicle conditions accounted for $35 \%$ of the total accidents, followed by untrained driving (27\%). The primary reason behind the massive percentage of road accidents on M2 was drowsy driving (33\%). On M3, the factor responsible associated with the maximum number of road accidents was the vehicle condition. Vehicle conditions accounted for $49 \%$ of the total number of accidents followed by untrained driving (27\%). In terms of time, the road accident on M1 was relatively higher during the daytime (06:00-12:00). M2 suffered a significant portion of road accidents in late-night (00:00-06:00). However, no substantial variation of road accidents on M3 was evident in this study. Regarding, the months of occurrence, road accidents were relatively higher during the summer in M1 and M2 as compared to the winter season; however, no variation among road accidents was examined on M3. Afterward, the black spots on each motorway are identified by reliability analysis, and their coordinates are also mentioned.

There are several recommendations proposed to minimize road accidents on the selected motorways. Vehicle condition is the factor responsible for the maximum number of road accidents on M1. It is strongly advised not to drive the vehicle on the road unless it is mechanically and technically fit. To ensure the vehicle fitness, check out the basic parameters of the vehicle before going on the road, such as; (a) headlights, (b) the battery level, (c) oil level, (d) tire air pressure, (e) windshield defogger, and (f) wiper blades. It must be ensured that the view through the rear-view mirror is not obstructed in any way. Installation of maintenance checking shops on different locations of the motorways would be beneficial. For M2, drowsy driving is responsible for the maximum number of road accidents. For the reduction of road accidents due to drowsy driving, it is recommended to arrange awareness campaigns for drivers and advise them to complete eight hours of sleep before drive. It is suggested that drivers do not drive continuously for more than four hours. Building rest areas at a suitable interval would be advantageous to facilitate drivers who suffer from driving fatigue and drowsiness. Installation of rumble strips every 10 $\mathrm{km}$ or $20 \mathrm{~km}$ on the straight portion of the road also reduces drowsy driving. The rumble strip creates some vibration and unique sound to keep the driver active. Drowsy driving can also be reduced by providing a warning system for lane departure. This warning system can be installed in the vehicle and warn the driver changes the line. This study concluded that untrained driving is also a significant contributory factor responsible for road accidents. It is suggested that government officials and concerned authorities should make strict rules for the issuance of driving license. It has already been demonstrated that driving without a driving license and proper driving training are significant factors for road accidents in Pakistani drivers [3]. The proper driving test should be conducted after proper driving training. Furthermore, strict penalties and fines would be imposed on the driver driving without a driving license. Concerned authorities should install large posters for new signs and rules to communicate with drivers. Furthermore, GIS should be used to analyze road accidents because road accident data can be retrieved and analyzed for traffic agencies. Road accident analysis is a very complex topic because it contains several factors. The road accident reports in the country must be well explained and appropriately formatted for future statistical and spatial analysis. Traffic police are responsible for reporting road accidents, so it is highly recommended to perform training sessions for traffic police to enhance the importance of road accident reports. This act would help identify the significant causes of road accidents and handle them properly to reduce road accidents in the country.

This study has some limitations. First, the volume of traffic is not considered for the chosen motorways due to unavailability. Second, gender-wise, age-wise, and day-wise road accident distribution was not conducted in this study. The analysis is based on the manually processed data collected from NHMP, so there are chances of human errors. Some of the conditions regarding contributory factors responsible for road accidents were extremely rare, which resulted in statistically insignificant results. The inclusion of demographic and socioeconomic factors responsible for road accidents in the country warrants 
investigation in the future. Likewise, studies need to be conducted using data for other motorways and national highways to examine variations in contributory factors to road accidents.

\section{ACKNOWLEDGMENT}

We acknowledge the financial support from the National Natural Science Foundation of China (No. 51578319 and No.51778340)

\section{REFERENCES}

1. WHO, "Global Status Report on Road Safety”, World Health Organization: Geneva, Switzerland, 2018.

2. Zhang X, Yao H., Hu G., Cui M., Gu Y., Xiang H., "Basic Characteristics of Road Traffic Deaths in China”, Iranian Journal of Public Health, Vol. 42, No.1, pp. 7-15, 2013.

3. Hussain M., Shi J., "Effects of proper driving training and driving license on aberrant driving behaviors of Pakistani drivers-A Proportional Odds approach", Journal of Transportation Safety and Security, pp. 1-19, 2019.

4. Azam K., Shakoor A., Shah R.A., Khan A., Shah S.A., Khalil M.S., "Comparison of fatigue related road traffic crashes on the national highways and motorways in Pakistan", Journal of Engineering and Applied Sciences, Vol. 33, No.2, pp. 47-54, 2014.

5. Statistics, P.B.o., "Pakistan Bureau of Statistics", Government of Pakistan, Islamabad, Pakistan, 2017.

6. McGwin J.G., Brown D.B., "Characteristics of traffic crashes among young, middle-aged, and older drivers", Accident Analysis and Prevention, Vol. 31, No. 3, pp. 181-198, 1999.

7. McCartt A.T., Shabanova V.I., Leaf W.A., "Driving experience, crashes and traffic citations of teenage beginning drivers", Accident Analysis and Prevention", Vol. 35, No. 3, pp. 311-320, 2003

8. Lam L.T., "Factors associated with young drivers' car crash injury: comparisons among learner, provisional, and full licensees", Accident
Analysis and Prevention, Vol. 35, No. 6, pp. 913920, 2003.

9. Gonzales M.M., Dickibson L.M., DiGuiseppi C., Lowerstein S.R., "Student drivers: A study of fatal motor vehicle crashes involving 16-year-old drivers", Annals of Emergency Medicine, Vol. 45, No. 2, pp. 140-146, 2005.

10. Rolison J.J., Hanoch Y., Wood S., Liu P.-J., "Risk-taking differences across the adult life span: a question of age and domain", Journals of Gerontology Series B: Psychological Sciences and Social Sciences, Vol. 69, No. 6: pp. 870-880, 2013.

11. Langford J., Koppel S., "Epidemiology of older driver crashes - Identifying older driver risk factors and exposure patterns”, Transportation Research Part F: Traffic Psychology and Behaviour, Vol. 9, No.5, pp. 309-321, 2006.

12. Hu P.S., Young J.R., Lu A., "Highway crash rates and age-related driver limitations: Literature review and evaluation of data bases", Technical Report, Oak Ridge National Lab, Department of Transportation, Washington DC, USA, 1993.

13. Kingham S., Sabel C.E., Bartie P., "The impact of the school run' on road traffic accidents: A spatiotemporal analysis", Journal of Transport Geography, Vol. 19, No. 4, pp. 705-711, 2011.

14. Blincoe L.J., Seay A.G., Zaloshnja E., Miller T.R., Romano E., Luchter S., Spicer R.S., "The economic impact of motor vehicle crashes 2000", National Highway Traffic Safety Administration, USA, January 2002.

15. McEvoy S.P., Stevenson M.R., McCartt A.T., Woodword M., Haworth C., Palamara P., Cercarelli R., "Role of mobile phones in motor vehicle crashes resulting in hospital attendance: a case-crossover study", BMJ, Vol. 331, No. 7514, 2005.

16. Singh S., "Road Traffic Accidents in India: Issues and Challenges. Transportation", Research Procedia, Vol. 25, pp. 4712-4723, 2017.

17. Bener A., Yildirim E., Ozkan T., Lajunen T., "Driver sleepness fatigue, careless behavior and risk of major vehicle crash and injury. Population based case and control study", Journal of Traffic and Transportation Engineering (English Edition), Vol. 4, No.5, pp. 496-502, 2017. 
18. Saxby D.J., Matthews G., Neubauer C., "The relationship between cell phone use and management of driver fatigue: It's complicated", Journal of Safety Research, Vol. 61, pp. 129-140, 2017.

19. Lewis I., Watson B., White K.M., Elliot B., "The beliefs which influence young males to speed and strategies to slow them down: informing the content of antispeeding messages", Psychology and Marketing, Vol. 30, No. 9, p. 826-841. 2013.

20. Ministry of Finance, G.o.P., Pakistan Economic Survey 2015-16. 2015-16.

21. Durrani F.. "Road accidents proving deadlier than terrorism", 2016; Available at: https://www.thenews.com.pk/print/112816Road-accidents-proving-deadlier-than-terrorism.

22. Bergel-Hayat R., Debbarh M., Antoniou C., Yannis G., "Explaining the road accident risk: weather effects", Accident Analysis and Prevention, Vol. 60, pp. 456-465. 2013.

23. Commandeur J.J.F., Bijleveld F.D., Bergel-Hayat R., Antoniou C., Yannis G., Papadimitriou E. "On statistical inference in time series analysis of the evolution of road safety", Accident Analysis and Prevention, Vol. 60, pp. 424-434, 2013.

24. Yannis G., Evgenikos P., Hoeglinger S., Bos N., Broughton J., Lawton B., "Comparative analysis of road safety parameters in the European motorways", Proceedings of the 1st European Road Infrastructure Congress, Leeds, UK, 2016.

25. Yannis G., Papadimitriou E., Evgenikos P., "Cost-benefit assessment of selected road safety measures in Greece", Proceedings of the 13th International Conference on Road Safety on Four Continents, Warsaw, 2005.

26. Yannis G., Evgenikos P., Papadimitriou E., "Best practice for cost-effective road safety infrastructure investments", Proceedings of the Conference of European Directors of Road (CEDR), 2009.

27. Papadimitriou E., Filtness A., Theofilatos A., Ziakopolous A., Quigley C., Yannis G., "Review and ranking of crash risk factors related to the road infrastructure", Accident Analysis and Prevention, Vol. 125, pp. 85-97, 2019. analysis of road networks", Transportøkonomisk institutt Oslo, 2007.

29. Aghajani M.A., Dezfoulian R.S., Arjroody A.R., Rezaei M., "Applying GIS to identify the spatial and temporal patterns of road accidents using spatial statistics (case study: Ilam Province, Iran)", Transportation Research Procedia, Vol. 25, pp. 2126-2138, 2017.

30. Hauer E., "Identification of sites with promise", Transportation Research Record, 1996. Vol. 1542, No. 1, pp. 54-60.

31. Erdogan S., Yilmaz I., Baybura T., Gullu M., "Geographical information systems aided traffic accident analysis system case study: city of Afyonkarahisar", Accident Analysis and Prevention, Vol. 40, No. 1, pp. 174-181. 2008.

32. Ghadi M., Török Á., "Comparison of Different Black Spot Identification Methods", Transportation Research Procedia", Vol. 27, pp. 1105-1112. 2017.

33. Chin H.C., Quddus M.A., "Applying the random effect negative binomial model to examine traffic accident occurrence at signalized intersections", Accident Analysis and Prevention, Vol. 35, No. 2, pp. 253-259, 2003.

34. Resende P.T.V., Benekohal R.F., "Effects of roadway section length on accident modeling. in Traffic Congestion and Traffic Safety in the 21st Century: Challenges, Innovations and Opportunities, Urban Transportation Division, ASCE; Highway Division, ASCE; Federal Highway Administration, USDOT; and National Highway Traffic Safety Administration, USDOT, 1997.

35. Peden M., Scurfield R., Sleet D., Mohan D., Hyder A.A., Jarawan E., Mathers C., "World report on road traffic injury prevention. 2004", World Health Organization Geneva, 2004.

36. Taylor M.C., Lynam D., Baruya A., "The effects of drivers' speed on the frequency of road accidents”, TRL Report 421, Transport Research Laboratory, Crowthorne, Berkshire, UK, 2000.

28. Elvik R., "State-of-the-art approaches to road accident black spot management and safety 